\title{
Hedging in English texts written by lower secondary pupils attending Norwegian schools
}

\author{
James Jacob Thomson \\ Universitetet i Stavanger
}

\begin{abstract}
This study analyses the use of hedges in English texts written by year nine ${ }^{1}$ pupils attending Norwegian lower secondary schools. Hedges are quantified in a corpus of 82 pupil texts using a taxonomy consisting of five hedging categories: Adaptors, Rounders, Plausibility Shields, Explicit Markers of Author Involvement and Verbal Fillers (Prince et al., 1980; SalagerMeyer, 1994; Holmes, 1986). As the pupils are school-level second language learners of English, each device is also deemed to be either accurately or inaccurately used based on grammar, well-formedness and appropriateness (Fetzer, 2004). The analyses are compared across topic, holistic ratings and formality. Texts in the corpus are written about two topics: sports and literary analyses of the novel Holes (Sachar, 1998). Texts about sports contain significantly more hedges than texts about Holes. Comparing accurate and inaccurate categories across holistic ratings, different results were produced when considering topic. Informally written texts about sports contain higher frequencies of accurately used devices than formally written texts about sports. The results suggest that topic and formality are the most significant factors affecting hedging use in this corpus. While hedging frequency overall does not seem to correlate with holistic ratings, overuse and inaccurate use of hedges seems to affect quality. Based on the results, it is argued that pupils may benefit from exposure to a wide range of accurately used devices.
\end{abstract}

\footnotetext{
1 "Year 9" is a term usually used in the UK, synonymous with "9 9 th grade" used in the United States, for pupils aged 13-14.
} 


\section{INTRODUCTION}

Hedging is a term applied to linguistic devices used for "withholding full commitment to statements" (Hyland, 1998, p. 3). The notion that scientific writing is objective and impersonal has contributed to negative attitudes towards using hedges in academic writing as they have been considered to connote personal views and subjectivity (Hyland, 1996, p. 477; Skelton, 1988, p. 38). Hyland (1998, p. 6) claims that hedging is misunderstood. He argues instead that hedges are crucial when tentatively making claims and when establishing writerreader relations in academic writing. For this study, hedges are considered to be devices that “indicate the writer's decision to recognize alternative voices and viewpoints and so withhold complete commitment to a proposition" (Hyland, 2005, p. 52).

Previous research on hedging in second language learner (L2) writing tends to analyse samples of academic texts written by either students or professionals (e.g. Vassileva, 2001; Hinkel, 2005; Hu and Cao, 2011). Such studies indicate that L2 writing is characterised by fewer hedging devices than native speaker writing, with the consequence that L2 writing may be perceived as "too direct", or "too tentative" (Hyland, 1998, p. 221). Hyland suggests that hedging should be taught at earlier educational levels (1998), but none of the reviewed research addresses hedging in lower secondary L2 texts, with the majority of studies focusing on tertiary-level writing instead. This research aims to address this gap by analysing hedges in English texts written by year nine pupils in the Norwegian school context.

While the Norwegian curriculum for English does not prescribe the teaching of specific linguistic structures, hedging can potentially be linked to the goals outlined for written communication. For example, one goal states that pupils should write "adapting the language to purposeful objectives and [.] to the recipient", which requires developing an awareness of formal and informal genres and using a relevant vocabulary (UDIR., 2013, p. 3).

This study ${ }^{2}$ investigates whether hedging use correlates with topic, holistic ratings and formality in 82 English texts written by year nine (13-14 year-old) pupils at two Norwegian lower secondary schools. The following research questions are investigated:

1. Does hedging use in year nine texts correlate with topic, holistic ratings and formality in terms of:

\footnotetext{
${ }^{2}$ This article is based on research conducted for the author's Master's thesis.
} 

a. Frequency?
b. Hedging category?
c. Accuracy?

The three variables topic, holistic ratings and formality, were chosen based on previous studies and based on the content of the corpus. Texts in the corpus were written about two main topics: sports and literary analyses. Previous research (Hinkel 2009) finds that topic affects hedging use, so topic is included as a variable. Previous research also compares how hedges are used in high and low-rated texts (e.g. Hyland and Milton, 1998) and, considering the range of abilities among the participating pupils, holistic ratings are included as a variable. Finally, some texts in the corpus were clearly written to be speech-like, so formality, although not included in previous research, is included as a variable based on criteria outlined by Szuchman (2014, pp. 17-18).

\section{PREVIOUS RESEARCH ON HEDGING}

Previous research shows that hedging is a prominent feature of written English (e.g. Skelton, 1988; Hyland, 1998). However, hedging use can be affected by a number of factors such as language (e.g. Vold, 2006), a text's purpose (e.g. Salager-Meyer, 1994) and a writer's proficiency (e.g. Hinkel, 2005). The pragmatic nuances of hedging can thus be difficult for language learners to master (e.g. Hinkel, 2005; Hu and Cao, 2011). To make matters more difficult, hedging seems to be overlooked by language learner textbooks (e.g. Hyland, 1994; Bromseth and Wigdahl, 2006a). Research has therewith given increasing attention to hedging in language learner writing (e.g. Hyland 1998; Mills and Dooley 2014). However, the majority of studies have focused on student and professional academic writing and only a handful of studies address hedging use in school-level writing, which is the focus of this study. This section presents both tertiary-level and school-level research, but it is recognised that comparing results across these different educational levels may be problematic.

In a study comparing hedging use in English academic essays written by Chinese, Japanese, Korean, Indonesian, Arabic, Vietnamese and native speakers, Hinkel (2005, p. 40) concludes that "L2 academic prose contained fewer hedging devices than that of NS writers". Hinkel shares examples of L2 prose which generally exhibit a less lexically varied, less 
effective hedging vocabulary, concluding that such traits are transferred from casual spoken discourse.

Other studies support Hinkel (2005), finding that learners of English often struggle to effectively use hedges in their writing (e.g. Vassileva, 2001; Hu and Cao, 2011). These studies put forward different explanations for why L2 speakers may struggle with hedging. First, learners may be unaware of how to use hedges appropriately, or of the necessity of hedging in English academia (Vassileva, 2001, pp. 87-88). Second, different languages may be grounded in different rhetorical traditions, meaning that while Socratic rhetoric is expected in English academia, a learner may be more familiar with, for example, Confucian rhetoric (Hinkel, 1997, p. 363; Tweed and Lehman, 2002). A third explanation may be differences in epistemological beliefs. For example, Anglo-American linguistic disciplines can be said to be grounded in pluralism, thus requiring more tentativeness than in Chinese linguistic disciplines, which can be said to be grounded in positivism (Hu and Cao, 2011, p. 2805).

Arguably, Norwegian is rhetorically similar to British and American English (e.g. Dahl, 2004; Vold, 2006), meaning that rhetorical and scientific traditions are unlikely to affect hedging in English texts written by pupils attending Norwegian lower secondary schools. On the other hand, pupils in this context may struggle to use hedges due to a lack of awareness of hedging.

In another study, Hinkel (2009) finds that modal verb use in university student writing is affected by topic. She finds that modal verbs are overused in topics that draw on personal experiences and socio-cultural background (2009, p. 667). Based on her results, Hinkel (2009, p. 681) suggests that giving students topics that do not depend on their personal experiences can "lead to less topic-sensitive and culturally dependent uses of language in L2 writing".

Among the limited research that investigates hedging in school-level writing, Hyland and Milton (1997) compare hedging in English texts written by Cantonese speakers and English speakers completing their final school year. They find that texts written by Cantonese speakers exhibit a more restricted range of hedging devices. However, the texts deemed to be of a higher quality use hedging conventions more similarly to the NS texts. Based on their results, Hyland and Milton argue that overlooking the teaching of hedging to L2 speakers "may be detrimental to leaner's academic and professional opportunities" (1998, p. 201). 
Dobbs (2014) looks at a range of organisational and stance markers, including hedges, in texts written by sixth, seventh and eighth graders attending American schools. Her findings show that pupils seem to struggle to integrate evidence into their writing and tend to make arguments strongly. Hedges in Dobbs' corpus seem considerably infrequent when considering investigations of academic writing, which find hedges are frequently used in relation to other organisational and stance markers (e.g. Hyland, 2005). Dobbs also considers essay quality, which is not affected by the frequency of hedges and other stance markers.

Finally, Mills and Dooley (2014) use examples of year six pupil argumentative NS texts to argue that hedging ought to be more explicitly taught at the school level. They cite some examples from pupil work and argue that these are inappropriately emotional in that they exhibit speech-like traits and underuse hedging devices. Mills and Dooley (2014, pp. 3839) argue that teaching hedging at this level would help pupils both to distinguish between features of speech and writing and to develop greater rhetorical prowess.

The present study aims to contribute to the small pool of school-level hedging research by investigating hedging use in a corpus written by year nine learners of English attending Norwegian schools.

\section{METHODS}

This study involved quantifying hedging devices in a corpus of year nine pupil texts written at two Norwegian lower secondary schools in Western Norway. The sample can be considered to be a convenience sample in that the schools involved were proximal to the research institution (Dörnyei, 2007, p. 98). To collect texts, the researcher cooperated with teachers at the schools and parental consent was received on behalf of all participating pupils. A corpus was built specifically to investigate hedging in year nine English language learner writing as no corresponding corpus of texts was available.

The textual data was written by 82 year nine pupils at the aforementioned two lower secondary schools. This comprised 33 boys and 25 girls at school A, and 10 boys and 14 girls at school B. The texts were rated from one (the lowest grade) to six (the highest grade), with an average of 3.8. The holistic ratings used were those set by the teachers. In this grading system, plusses and minuses can also be used, but were disregarded for this study. For 
example, a text that received a five plus was considered to have received a five. The texts contained from 27 to 1155 words and the corpus consists of 39,645 words in total.

In Norway, English as a subject is taught from the first year of schooling, when pupils are five to six years of age. That is to say that the majority of participants were in their ninth year of learning English. While some pupils may have had more or less experience with English, all the pupils were considered to be proficient enough to participate in ordinary tuition.

The texts collected were written for ordinary school evaluations. This approach, instead of asking all the pupils at both schools to write about a single topic, was adopted for two reasons. Firstly, it seemed less likely that teachers would participate if they were required to use lesson time on non-curricular activities. Secondly, fabricating a writing task may have produced inauthentic data. By collecting texts written for ordinary evaluations, the teaching and assessment procedures could take place as usual. The data should thus represent the types of texts usually written in this context.

The writing topic and the writing conditions differed at each school. At school A, the pupils wrote texts with a sports theme as part of a timed test lasting 90 minutes. The pupils at school B, on the other hand, wrote literary analyses of the novel Holes (Sachar, 1998) and were able to write in lessons and as homework over the course of several days, a method called "process-oriented writing" (Lee, 2006).

Since a reasonably large number of words and phrases can have a hedging function, five hedging categories were used in order to sensitively quantify hedging devices. Different hedging taxonomies (e.g. Hinkel 2005; Crompton, 1997) were considered and the hedging categories here were chosen based on what seemed most useful for analysing this particular corpus. It was difficult to apply a single previous taxonomy to the data set, so the five hedging categories were combined from research by Prince et al. (1980), Salager-Meyer (1994) and Holmes (1986). The five categories are as follows:

1. Adaptors (a sub-category of approximator; Prince et al., 1980, p. 8-9) can be used to show when an item does not entirely match a category it is attributed to, as in the following example: 


\section{Nordic Journal of Modern Language Methodology}

$[1]^{3}$ it rarely snows here so that is kind of sad...

Other Adaptors in this study included: almost, sort of, in a sense.

2. Rounders (a sub-category of approximator; Prince et al., 1980, p. 10) are words used when precise numbers are not available or when someone wishes to describe a "range of items". Also categorised as Rounders are devices that affect scale in an abstract sense: when there is no literal numeric scale involved in the statement. Such devices are comparable to Hinkel's (2005, p. 38) downtoners in that they "reduce the qualitative and emotive implications of verbs, adjectives, and abstract nouns". In the following example, a Rounder is used rather than precise numbers:

[2] Stord had some chances to score...

Other Rounders in this study included: almost, sometimes, bit, little.

3. Plausibility Shields (Prince et al., 1980, p. 13) are words used to convey uncertainty in that a statement may be incorrect, as in the following example:

[3] A person that loves dancing might not be well suited for, for example boxing. Other Plausibility Shields in this study included: can, probably, could, maybe.

4. Explicit Markers of Author Involvement (hereafter EMAIs; Salager-Meyer, 1994, p. 154) detract from the strength of a statement, differing from the other categories in that these devices involve personal pronouns such as "I", as in the following example: [4] I think it's amazing how the author made us feel all of these different emotions... Other EMAIs in this study included: my opinion, I believe, I mean.

5. Verbal Fillers (Holmes, 1986, p. 6) are usually considered features of speech and have not been included in the hedging taxonomies used to analyse writing reviewed for this research. These devices are used to give speakers time to formulate or reformulate what they want to say. Verbal fillers were present in pupil texts and were quantified when they had a clear hedging function. Example [5] is counted as a hedge

\footnotetext{
${ }^{3}$ The examples in this article are directly quoted from texts in the corpus.
} 


\section{Nordic Journal of Modern Language Methodology}

as it seems to mark hesitancy, while example [6] is not counted as a hedge as it seems to introduce an answer an interviewee is giving to a question.

[5] Well let's start of by saying...

[6] Well sir, AWP is a weapon commonly used by many in the game...

Other Verbal Fillers in this study included: anyway, just.

Some types of hedging device may be categorised differently based on the context in which they are used. For example, in [7], almost is an Adaptor and in [8], almost is a Rounder:

[7] Buildering is almost bouldering.

[8] this became known almost everywhere in the world...

When hedges were quantified and categorized accordingly, they were then considered to be either accurate or inaccurate. It seemed necessary to investigate accuracy here due to the pupils' level of proficiency. Criteria for accurate hedging use were devised based on theory used by Ishikawa (1995) and Fetzer (2004). Ishikawa (1995, p. 59) considers accuracy "with respect to discourse, vocabulary, grammar and style" in order to measure written proficiency among language learners. None of the reviewed research has specifically addressed accuracy when quantifying hedges. Three criteria cited by Fetzer (2004) were therefore used to consider hedging accuracy: grammar [9], well-formedness [10] and appropriateness [11]. An accurate hedge should be: grammatically correct; well-formed in that it should not detract from the comprehensibility of the sentence; and appropriate in that it adheres to the writer's intended formality. The following extracts exemplify how each of these criteria may not be met ([11] is taken from an otherwise formally written text):

[9] If you broadcasted real sports [...] could there be a chance that some games producers would watch the match.

[10] I had enough Sport on my TV it is almost sports the hole day

[11] We don't shower in like 1 hour.

Six texts were considered informal in that pupils seemingly intended to write in a speech-like style (Szuchman, 2014, p. 17-18). In [12], the pupil explicitly makes their speech-like style clear: 
[12] I'm going to tell you a bit of its story and why we all love this sport all too much.

Hedges were thus identified as belonging to one of the five categories and considered to be either accurate or inaccurate. Devices in each text were quantified as raw numbers and per one hundred words. The author conducted the analysis of the corpus. A second rater analysed three texts and their analyses exhibited a high level of agreement with the author's. The results were tested for statistical significance using SPSS (2012) using a p-value of $p=.05$.

\section{RESULTS}

This section presents the frequencies of each accurate and inaccurate hedging category according to topic, holistic ratings and formality. Besides Table 1, the results from texts about each topic are presented separately, as the quantitative analyses of these data produced considerably different results. The results regarding hedging frequency in formal and informal texts are only taken from school A, as no texts at school B were informally written.

Table 1 shows the frequencies of hedges at each school and in the corpus in total, both as raw frequencies and per one hundred words. In the corpus, there were five texts that contained no hedges (three from school A and two from school B), while 77 did contain hedges. There are both accurate and inaccurate instances of almost every hedging category in texts collected from both schools. By and large, these results support the idea that hedging is a ubiquitous feature of writing (e.g. Hyland, 1998), also in the lower-secondary L2 context.

Table 1 further shows that hedging was more frequent at school A, where pupils used almost two hedges per one hundred words, while pupils at school B used less than one hedge per one hundred words. However, the distributions were similar at both schools in that Rounders were most frequent followed by Plausibility Shields and then Explicit Markers of Author Involvement (EMAIs). Adaptors and Verbal Fillers were the least frequently used categories. Verbal fillers were particularly infrequent at school B, which can perhaps be attributed to the nature of the literary analysis tasks and the process-oriented writing conditions. Each hedging category was more frequently accurate in almost all cases. This suggests that a majority of pupils were able to use hedges that were grammatically correct, well-formed and appropriate. However, over a quarter of the total number of hedges were used inaccurately, supporting Mills and Dooley (2014), who claim hedging ought to be taught more explicitly. 


\section{Nordic Journal of Modern Language Methodology}

Rounders were the most frequent and most varied category of hedging device in the data, with 48 types occurring accurately 0.69 times and inaccurately 0.19 times per one hundred words. Of the variety of types present in the data, some was by far the most frequent, occurring 0.27 times per one hundred words. The second most frequent Rounder was "almost", occurring 0.08 times per one hundred words. These results indicate that pupils most often use hedging devices when exact numbers are not available or to express a "range of items" (Prince et al., 1980, p. 10) and often express this using the Rounder some. Example [13] is taken from a text where some occurred four times, although other Rounders, such as few, could have been chosen to vary the vocabulary:

[13] I would like to share some thoughts

Table 1. Frequencies of accurate and inaccurate devices belonging to each hedging category at each school and in total in the corpus (total number and per one hundred words)

\begin{tabular}{|c|c|c|c|c|c|c|c|c|c|c|c|c|}
\hline & \multicolumn{2}{|c|}{ Total } & \multicolumn{2}{|c|}{ Adaptors } & \multicolumn{2}{|c|}{ Rounders } & \multicolumn{2}{|c|}{$\begin{array}{c}\text { Plausibility } \\
\text { Shields }\end{array}$} & \multicolumn{2}{|c|}{ EMAIs } & \multicolumn{2}{|c|}{$\begin{array}{l}\text { Verbal } \\
\text { Fillers }\end{array}$} \\
\hline & Acc. & Inacc. & Acc. & Inacc. & Acc. & Inacc. & Acc. & Inacc. & Acc. & Inacc. & Acc. & Inacc. \\
\hline \multicolumn{13}{|c|}{ School A (Sports; 25,470 words) } \\
\hline Sum & 358 & 121 & 15 & 9 & 217 & 49 & 53 & 33 & 53 & 15 & 20 & 15 \\
\hline Mean & 1.41 & 0.48 & 0.26 & 0.16 & 3.74 & 0.84 & 1.14 & 0.57 & 0.91 & 0.26 & 0.34 & 0.26 \\
\hline \multicolumn{13}{|c|}{ School B (Holes; 14,175 words) } \\
\hline Sum & 83 & & 8 & 2 & 50 & 21 & 20 & 4 & 23 & 2 & 0 & 2 \\
\hline Mean & 0.59 & 0.22 & 0.33 & 0.08 & 2.08 & 0.17 & 0.83 & 0.08 & 0.96 & 0.08 & 0 & 0.08 \\
\hline \multicolumn{13}{|c|}{ Total $(39,645$ words $)$} \\
\hline Sum & 472 & 172 & 23 & 11 & 267 & 70 & 86 & 37 & 76 & 17 & 20 & 17 \\
\hline Mean & 1.19 & 0.43 & 0.05 & 0.03 & 0.69 & 0.19 & 0.21 & 0.12 & 0.19 & 0.05 & 0.04 & 0.04 \\
\hline
\end{tabular}

Plausibility Shields were the second most frequent device present, occurring accurately 0.21 times and inaccurately 0.12 times per one hundred words. Can was the most frequent type, used in total 0.13 times per one hundred words. Of all the types of inaccurately used hedge in the data set, can was the most frequent, occurring inaccurately 0.06 times and accurately 0.07 


\section{Nordic Journal of Modern Language Methodology}

times per one hundred words. This may be attributed to the word's phonetic similarity with the Norwegian word kan, which is perhaps more often translated to the English word may. The word is thus subject to acting as a false friend: words in two language that sound the same, but have two different meanings (Gutknecht, 2001, p. 698). Example [14] shows an instance of can acting as a false friend where the word may would usually be used.

[14] you can know, the word zombie come from Africa

There were 0.24 EMAIs per one hundred words in total in the data. There were 20 types of EMAI, but $I$ think was the most common, occurring 0.13 times per one hundred words. The second most common EMAI was my opinion, which occurred 0.02 times per one hundred words, suggesting pupils tended to resort to using I think rather than using other EMAIs.

Table 2 presents the median frequencies of each category of hedging device based on the topic at schools A (sports) and B (Holes). A Mann-Whitney U test was used to test for statistical significance as the data in each of the groups was not normally distributed. The results show that pupils who wrote about sports used significantly more accurate $(p=.00)$ and inaccurate $(\mathrm{p}=.02)$ hedging devices in total than those that wrote about Holes (Sachar, 1998).

Table 2. Frequencies of accurate and inaccurate hedges in texts about each topic (median per one hundred words)

\begin{tabular}{|r|c|c|c|c|c|c|c|}
\hline \multicolumn{2}{|c|}{} & Total & Adaptors & Rounders & $\begin{array}{c}\text { Plausibility } \\
\text { Shields }\end{array}$ & EMAIs & $\begin{array}{c}\text { Verbal } \\
\text { Fillers }\end{array}$ \\
\cline { 2 - 9 } \multicolumn{2}{|c|}{} & Median & Median & Median & Median & Median & Median \\
\hline Accurate & Sports & $* 1.17$ & 0.00 & $* 0.72$ & $* 0.20$ & 0.00 & 0.00 \\
& Holes & $* 0.50$ & 0.00 & $* 0.28$ & $* 0.00$ & 0.05 & 0.00 \\
\hline Inaccurate & Sports & $* 0.37$ & 0.00 & 0.00 & $* 0.00$ & 0.00 & 0.00 \\
& Holes & $* 0.00$ & 0.00 & 0.00 & $* 0.00$ & 0.00 & 0.00 \\
\hline
\end{tabular}

Of the accurate hedging categories, Rounders $(\mathrm{p}=.00)$ and Plausibility Shields $(\mathrm{p}=.01)$ were significantly higher in texts written about sports. Of the inaccurate categories, Plausibility Shields $(\mathrm{p}=.04)$ were significantly higher in texts written about sports. These results imply pupils were more inclined to use hedging devices when writing about sports than when 


\section{Nordic Journal of Modern Language Methodology}

writing literary analyses. These results may be explained by several factors, one being that sports may be more integral to pupils' lives than the content of the novel Holes, so they may have stronger personal opinions about the topic, supporting Hinkel's (2009) findings.

Table 3. Accurately used hedges in texts written at School B at each grade level and pvalues of one way ANOVA (mean per one hundred words)

\begin{tabular}{|r|r|r|r|r|r|}
\hline & Total & Adaptors & Rounders & $\begin{array}{c}\text { Plausibility } \\
\text { Shields }\end{array}$ & EMAIs \\
\cline { 2 - 6 } Grade & Mean & Mean & Mean & Mean & Mean \\
\hline 2 & 2.04 & .00 & 1.08 & .00 & .85 \\
3 & 0.27 & .00 & .20 & .08 & .03 \\
4 & 0.66 & .06 & .48 & .02 & .12 \\
5 & 1.08 & .09 & .30 & .30 & .34 \\
6 & .93 & .10 & .41 & .31 & .10 \\
P-value & .275 & $* .000$ & $* .000$ & .465 & $* .007$ \\
\hline
\end{tabular}

The one-way ANOVA test was used to compare both accurate and inaccurate hedging use across grades. In terms of accurate hedging use, statistically significant differences were only found at school B, as presented in Table 3 (there were no accurate Verbal Fillers, so this category is excluded from the table). These results show that Adaptors $(p=.000)$, Rounders $(\mathrm{p}=.000)$ and EMAIs $(\mathrm{p}=.007)$ significantly varied according to grades. For Adaptors, the trend seems to be that this category is more frequent in higher-rated texts, but drawing conclusions seems problematic since the frequencies of Adaptors are so low. Both Rounders and EMAIs are most frequent in grade 2 texts, suggesting that an overuse of these devices may detract from a text's quality. The results seem otherwise somewhat randomly distributed. In order to make firmer conclusions, a larger data set would be needed. Running Tamhane's post hoc test revealed that the significant differences seem to be a result of cumulative effects and there were no significant differences across individual grades. 
Table 4. Inaccurately used hedges in texts written at School A at each grade level and pvalues of one way ANOVA (mean per on hundred words)

\begin{tabular}{|r|r|r|r|r|r|r|}
\hline & Total Hedges & Adaptors & Rounders & $\begin{array}{c}\text { Plausibility } \\
\text { Shields }\end{array}$ & EMAIs & $\begin{array}{c}\text { Ferbal } \\
\text { Graders }\end{array}$ \\
\cline { 2 - 7 } & Mean & Mean & Mean & Mean & Mean & Mean \\
\hline 1 & .00 & .00 & .00 & .00 & .00 & .00 \\
2 & .05 & .09 & .13 & .57 & .17 & .00 \\
3 & .02 & .34 & .03 & .07 & .05 \\
4 & .51 & .02 & .14 & .17 & .03 & .07 \\
5 & .43 & .06 & .24 & .10 & .05 & .06 \\
6 & .50 & .00 & .04 & .04 & .04 & .00 \\
P-Value & .11 & 0.060 & 0.574 & $* 0.001$ & 0.069 & 0.623 \\
\hline
\end{tabular}

Tables 4 and 5 present the frequencies of inaccurately used hedges across grades at schools $\mathrm{A}$ and B, respectively. At school A, Plausibility Shields $(\mathrm{p}=.001)$ are the only category significantly linked to textual quality. The total frequencies of inaccurate hedges $(p=.051)$ also almost significantly correlate with textual quality. The greatest differences are between the grade 2 and grade 6 texts, with grade 2 containing the highest frequencies of inaccurate hedges and grade 6 text containing the lowest frequencies. The results suggest that pupils who wrote lower quality texts about sports struggled to use Plausibility Shields with accurate grammar, well-formedness and formality.

At school B, inaccurate Adaptors $(\mathrm{p}=.000)$, Rounders $(\mathrm{p}=.041)$ and total hedges $(\mathrm{p}=$ .036), correlate with textual quality. Similarly to school A, these categories are more inaccurately used in grade 2 texts. There was one text that received a grade 6 at this school, which notably contained no inaccurately used hedges. The remaining inaccurate categories are infrequent and seemingly randomly distributed.

When considering the results from both schools, it seems that inaccurate use of hedges can detract from a text's quality, but no single hedging category is of particular difficulty. Writing about different topics may make different hedging demands, which could explain the variation in the results regarding different inaccurate hedging categories. For both schools, running Tamhane's post hoc test revealed that the significant differences seem to be a result 


\section{Nordic Journal of Modern Language Methodology}

of cumulative effects. The results in Tables 4 and 5 indicate that hedging does not correlate with written quality, supporting Dobbs' (2014) findings. However, overuse and inaccurate use of hedges may correlate with lower textual quality and low frequencies of inaccurate hedges may correlate with higher textual quality.

Table 6. Accurate and inaccurate hedges in informal and formal texts written about sports (median frequencies per one hundred words)

\begin{tabular}{|r|r|rr|}
\hline \multirow{2}{*}{ Style } & \multicolumn{2}{|c|}{ Total Accurate Hedges } & \multicolumn{2}{|c|}{ Total Inaccurate Hedges } \\
\cline { 2 - 4 } & Median & Median \\
\hline Informal & $* 3.14$ & & 0.60 \\
& & $* 1.06$ & \\
Formal & & & 0.35 \\
\hline
\end{tabular}

Table 5. Inaccurately used hedges in texts written at School B at each grade level and pvalues of one way ANOVA (mean per one hundred words)

\begin{tabular}{|c|c|c|c|c|c|c|}
\hline \multirow[b]{2}{*}{ Grade } & Total Hedges & Adaptors & Rounders & $\begin{array}{c}\text { Plausibility } \\
\text { Shields }\end{array}$ & EMAIs & $\begin{array}{l}\text { Verbal } \\
\text { Fillers }\end{array}$ \\
\hline & Mean & Mean & Mean & Mean & Mean & Mean \\
\hline 1 & . & & & & & \\
\hline 2 & .95 & .32 & .64 & .00 & .00 & .00 \\
\hline 3 & .18 & .00 & .04 & .05 & .02 & .06 \\
\hline 4 & .17 & .00 & .17 & .00 & .00 & .00 \\
\hline 5 & .38 & .04 & .20 & .11 & .02 & .00 \\
\hline 6 & .00 & .00 & .00 & .00 & .00 & .00 \\
\hline P-value & $* .036$ & $* .000$ & $* .041$ & .652 & .825 & .562 \\
\hline
\end{tabular}

Six of the texts about sports at school A were written in an informal style. ${ }^{4}$ These texts were awarded grades from 2 to 6 . Table 6 presents the median frequencies of accurately and inaccurately used hedging devices in texts about sports according to formality. A Mann-

\footnotetext{
${ }^{4}$ All of the texts written about Holes at school B were deemed to be written in a formal style.
} 


\section{Nordic Journal of Modern Language Methodology}

Whitney $U$ test, used to account for non-normal data distribution, revealed that accurately used hedges were used significantly more frequently in texts written in an informal style $(\mathrm{p}=$ .001). Hedges of all categories, besides Plausibility Shields, were significantly higher in informal texts (Adaptors: $\mathrm{p}=.011$; Rounders: $\mathrm{p}=.030$; Explicit Markers of Author Involvement: $\mathrm{p}=.003$; Verbal Fillers: $\mathrm{p}=.000$ ). This suggests that, when writing texts in an informal, speech-like style, pupils at this level are able to accurately utilise a greater number of hedging devices. This could imply that lower secondary pupils are more familiar with spoken than written conventions in English.

Overall, hedging is largely a ubiquitous feature of writing at this educational level. While hedging may only play a small role in textual quality, the results indicate that hedging can present various challenges for lower secondary learners of English. While a large number of hedging types are present, pupils frequently resort to using a handful of devices. It also seems that overuse and inaccurate use of hedging can detract from a text's quality. Finally, results indicate that pupils are more able to accurately use hedges when writing in an informal style. Considering these results, pupils may benefit from a greater awareness of what hedges are and how to use them accurately.

\section{DISCUSSIONS}

This discussion begins by addressing the total frequencies of each category of hedge before addressing topic, holistic ratings and formality. Previous research is considered, but any comparisons are tentatively made as none of the reviewed research has analysed hedging use in L2 writing at this level.

In the corpus, hedging devices were present in 77 of 82 texts, supporting the notion that hedging is a ubiquitous feature of written English (e.g. Hyland, 1998). The results suggest, furthermore, that Norwegian year nine pupils are more frequently able to use hedges accurately in terms of grammar, well-formedness and appropriateness when writing in English. However, over a quarter of hedging devices were used inaccurately and while there were a large number of different types of hedge present in the data, pupils often resorted to using the same limited palette of hedging devices, some, can and I think being most frequent. Based on Hinkel's (2005, p. 40) findings that "L2 academic prose contained fewer hedging 
devices than that of NS writers", further research could compare lower secondary level NS and L2 writing.

The topic of texts in this corpus significantly correlated with hedging use. Sports texts contained more hedging overall than literary analyses. In a similar vein to Hinkel's (2009) findings, the higher frequency of hedges in sports texts may be down to pupils having more personal experience with sports than they have with literary analyses of the book Holes.

The results suggest that hedging frequency overall does not correlate with textual quality. However, overuse and inaccurate use of hedges may detract from a text's quality. Regarding overuse, grade 2 texts at school B contained the highest frequencies of accurate Rounders and Explicit Markers of Author Involvement (EMAIs). Mills and Dooley (2014) argue that pupils may transfer spoken conventions into their writing work. It may be the case that the overuse of Rounders and EMAIs in grade 2 texts reflect inappropriately speech-like styles in these texts. Frequencies of Rounders and EMAIs do not seem to stand out at any other grade levels, suggesting moderate use of these hedging categories does not affect textual quality.

The inaccurately used categories were different at schools $\mathrm{A}$ and $\mathrm{B}$, but the trend at both schools is for inaccurate hedges to occur most frequently in grade 2 texts. Significantly correlating with grade were inaccurate Plausibility Shields at school A and inaccurate Adaptors and Rounders at school B. At both schools, grade 6 texts contained the lowest frequencies of inaccurate hedges. These results suggest that inaccurate hedging may contribute to texts receiving either the highest or lowest grades, but that other features are prioritized at other grade levels. The results also suggest that different topics can make different hedging demands, in that different categories were inaccurately used at each school, again reminiscent of Hinkel's findings (2009).

Regarding formality, the findings of this study show that pupils who wrote about sports in an informal speech-like style used significantly more accurate hedges than those who wrote in a more formal style. The case may be that pupils were more familiar with informal spoken conventions than with formal written conventions. As none of the reviewed literature addressed hedging and formality, further research could compare larger samples of formal and informal writing. 
These findings indicate that pupils at this educational level could benefit from greater exposure to pragmatic features such as hedging. By demonstrating how to accurately use a wider range of hedging devices, teachers may help pupils to master this nuanced linguistic feature. This supports Mills and Dooley (2014, p. 39), who argue that pupils should be taught a "greater range of advanced hedging techniques". To investigate this further, research could use larger corpora of both NS and L2 lower secondary writing and could analyse the data for other pragmatic features, such as intensifiers (e.g. Hinkel, 2005; Dobbs, 2014) and selfmentions (e.g. Hyland, 2002).

\section{CONCLUSIONS}

The aim of this study was to investigate hedging use in texts written by year nine learners of English attending Norwegian schools. While hedging has tended to be negatively regarded in academia (e.g. Skelton, 1988, p. 37), these findings show that hedging devices were present in most texts, supporting the idea that hedging is generally a ubiquitous feature of written English (e.g. Hyland, 1998). Regarding topic, hedging was most frequent in informal texts written about sports and least frequent in literary analyses of the book Holes. Regarding formality, accurate hedges were more frequent in speech-like texts than formally written texts. This suggests that writing about a familiar topic in a speech-like style is likely to stimulate greater hedging use than when writing about a less familiar topic in a formal style, supporting Hinkel's (2009) findings.

Hedging did not strongly correlate with holistic ratings, suggesting that other criteria are prioritized when marking pupil work. However, overuse and inaccurate hedging use seemed to characterize texts of the lowest quality. Furthermore, texts of the highest quality contained particularly few inaccurately used hedges. While a majority of pupils seemed to be able to accurately use hedges, the overuse and inaccurate use of hedges in grade 2 texts, as well as the high frequencies of a limited set of types present in the corpus, may be cause for concern. Previous research recognises that explicitly teaching hedging would be beneficial for language learners at the tertiary level (e.g. Hinkel, 2005; Hyland, 1998). This study supports the notion that hedging tuition would also benefit pupils at earlier educational levels (e.g. Mills and Dooley, 2014), also in the L2 context. Teachers may be able to help pupils 


\section{Nordic Journal of Modern Language Methodology}

undertaking text writing tasks by making them aware of what hedging is, equipping them with a wide range of hedging devices, and exposing them to accurate hedging use.

\section{REFERENCES}

Biber, D., Johansson, S., Leech, G., Conrad, S., \& Finegan, E. (1999). Longman Grammar of Spoken and Written English. Harlow: Longman.

Bromseth, B. H., \& Wigdahl, L. (2006a). New Flight 1 Textbook. Oslo: J.W. Cappelens Forlag AS.

- (2006b). New Flight 1 Workbook. Oslo: J.W. Cappelens Forlag AS.

- (2006c). New Flight 2 Textbook. Oslo: J.W. Cappelens Forlag AS.

- (2006d). New Flight 2 Workbook. Oslo: J.W. Cappelens Forlag AS.

- (2006e). New Flight Grammar. Oslo: J.W. Cappelens Forlag AS.

- (2007a). New Flight 3 Textbook. Oslo: J.W. Cappelens Forlag AS.

- (2007b). New Flight 3 Workbook. Oslo: J.W. Cappelens Forlag AS.

Dahl, T. (2004). Textual metadiscourse in research articles: a marker of national culture or of academic discipline? Journal of Pragmatics, 36(10), 1807-1825.

Dobbs, Christina L. (2013). Signaling organization and stance: Academic language use in middle grade persuasive writing. Reading and Writing, 27(8), 1327-1352.

Dörnyei, Z. (2007). Research Methods in Applied Linguistics: Quantitative, Qualitative and Mixed Methodologies (pp. 95-123). Oxford: Oxford University Press.

Fetzer, A. (2004). Recontextualizing Context: Grammaticality Meets Appropriateness. Amsterdam: John Benjamins Publishing Company.

Gutknecht, C. (2001). Translation. In Aronoff, M. \& Miller, J. R. (Eds.), The Handbook of Linguistics. Oxford: Blackwell Publishers Ltd.

Hinkel, E. (1997). Indirectness in L1 and L2 academic writing. Journal of Pragmatics, 27(3), 361-386.

- (2005). Hedging, inflating, and persuading in L2 academic writing. Applied Linguistic Learning, 15(1\&2), 29-53.

- (2009). The effects of essay topics on modal verb uses in L1 and L2 academic writing. Journal of Pragmatics, 41(4), 667-683. 


\section{Nordic Journal of Modern Language Methodology}

Holmes, J. (1986). Functions of you know in women's and men's speech. Language in Society, $15(1), 1-22$.

Hu, G. \& Cao, F. (2011). Hedging and boosting in abstracts of applied linguistics articles: A comparative study of English- and Chinese-medium journals. Journal of Pragmatics, 43(11), 2795-2809.

Hyland, K. (1994). Hedging in academic writing and EAP textbooks. English for Specific Purposes, 13(3), 239-256.

- (1996) Nurturing hedges in the ESP curriculum. System, 24(4), 477-490.

- (1998). Hedging in Scientific Research. Amsterdam: John Benjamin's Publishing Company.

- (2001). Humble servants of the discipline? Self-mention in research articles. English for Scientific Purposes, 20(3), 207-226.

- (2005). Metadiscourse: exploring interaction in writing. London: Continuum.

Hyland, K. and Milton, J. (1997) Qualification and certainty in L1 and L2 students' writing. Journal of Second Language Writing, 6(2), 183-205.

IBM Corp. (2012). IBM SPSS Statistics for Windows, Version 21.0. Armonk, NY: IBM Corp.

Ishikawa, S. (1995). Objective measurement of low-proficiency EFL narrative writing. Journal of Second Language Writing, 4(1), 51-70.

Lakoff, G. (1973). Hedges: A study in meaning criteria and the logic of fuzzy concepts. Journal of Philosophical Logic, 2, 458-508.

Lee, Y. J. (2006). The process-oriented ESL writing assessment: Promises and challenges. Journal of Second Language Writing, 15(4), 307-330.

Lewin, B. A. (2005). Hedging: an exploratory study of authors' and readers' identification of 'toning down' in scientific texts. Journal of English for Academic Purposes, 4(2), 163 178.

Mills, Kathy \& Karen Dooley. (2014). Teaching persuasive texts: Building a language of evaluation through hedging and moderated intensification. Literacy Learning: the Middle Years, 22(3), 33- 41.

Patton, M. (2002). Qualitative Research and Evaluation Methods. London: Sage Publications. Prince, E. F., Frader, J. \& Bosk, C. (1980). On hedging in physician-physician discourse. Presented at the AAAL Symposium on Applied Linguistics in Medicine. Retrieved from 


\section{Nordic Journal of Modern Language Methodology}

(19.11.2017):

http://www.cs.columbia.edu/ prokofieva/CandidacyPapers/Prince_Hedging.pdf

Sachar, L. (1998). Holes. New York: Yearling.

Salager-Meyer, F. (1994). Hedges and textual communicative function in medical English written discourse. English for Specific Purposes, 13(2), 149-170.

Skelton, J. (1988). The care and maintenance of hedges. ELT Journal vol. 42(1), 37-43.

Szuchman, L. T. (2014). Writing with Style: APA Style Made Easy, Sixth Edition. Wadsworth: Cengage Learning.

Thomson, J. J. (2016). Hedging in Year Nine Girls' and Boys' Written English in Norwegian Schools. Master's thesis. University of Stavanger.

Tweed, R. G., \& Lehman, D. R. (2002). Learning Considered Within a Cultural Context: Confucian and Socratic Approaches. American Psychologist, 57(2), 89-99.

Utdanningsdirektoratet (UDIR.) (2011). Engelsk: Veiledende nasjonale kjennetegn på måloppnåelse for standpunktvurdering etter 10. trinn. Kunnskapsdepartementet. Retrieved from (19.11.2017):

http://www.udir.no/globalassets/upload/vurdering/kjennetegn/engelsk_kjennetegn_bm . $\mathrm{pdf}$

- (2013). English Subject Curriculum. Kunnskapsdepartementet. Retrieved from (19.11.2017): http://www.udir.no/k106/ENG1-03

Vassileva, I. (2001). Commitment and detachment in English and Bulgarian academic writing. English for Specific Purposes 20, 83-102.

Vold, E. T. (2006). Epistemic modality markers in research articles: a cross-linguistic and cross-disciplinary study. International Journal of Applied Linguistics, 16(1), 61-87. 